\title{
In vitro activities of Acacia nilotica (L.) Delile bark fractions against Oral Bacteria, Glucosyltransferase and as antioxidant
}

\author{
Ali Mahmoud Muddathir ${ }^{1,2^{*}}$, Ebtihal Abdalla M. Mohieldin ${ }^{1,3}$ and Tohru Mitsunaga ${ }^{1}$
}

\begin{abstract}
Background: Dental caries and periodontal disease are the most common chronic infectious oral diseases in the world. Acacia nilotica was commonly known in Sudan as Garad or Sunt has a wide range of medicinal uses. In the present study, antibacterial activity of oral bacteria (Streptococcus sobrinus and Porphyromonas gingivalis), inhibitory activity against glucosyltransferase (GTF) enzyme and antioxidant activity were assayed for methanolic crude extract of $A$. nilotica bark and its fractions.

Methods: Methanoilc crude extract of A. nilotica bark was applied to a Sephadex LH-20 column and eluted with methanol, aqueous methanol, and finally aqueous acetone to obtain four fractions (Fr1- Fr4). Furthermore, the crude extract and fractions were subjected to analytical high performance liquid chromatography (HPLC). The crude extract and its fractions were assayed for antibacterial activity against $S$. sobrinus and $P$. gingivalis using a microplate dilution assay method to determine the minimum inhibitory concentration (MIC) and minimum bactericidal concentration (MBC), as well as GTF inhibition and antioxidant activity using ABTS radical scavenging method.

Results: Fractions ( $\mathrm{Fr} 1$ and $\mathrm{Fr} 2$ ) exhibited MIC values of $0.3 \mathrm{mg} / \mathrm{ml}$ against the $P$. gingivalis. Additionally, $\mathrm{Fr} 2$ displayed MBC value of $1 \mathrm{mg} / \mathrm{ml}$ against two types of bacteria. Fr4 showed an especially potent GTF inhibitory activity with $I_{50}$ value of $3.9 \mu \mathrm{g} / \mathrm{ml}$. Fr1 displayed the best antioxidant activity with $\mathrm{IC}_{50}$ value of $1.8 \mu \mathrm{g} / \mathrm{ml}$. The main compound in Fr1 was identified as gallic acid, and Fr2 was mostly a mixture of gallic acid and methyl gallate.

Conclusions: The results obtained in this study provide some scientific rationale and justify the use of this plant for the treatment of dental diseases in traditional medicine. A. nilotica bark, besides their antibacterial potentiality and GTF inhibitory activity, it may be used as adjuvant antioxidants in mouthwashes. Further studies in the future are required to identify the rest of the active compounds.
\end{abstract}

Keywords: Streptococcus sobrinus, Porphyromonas gingivalis, Glucosyltransferase enzyme, Acacia nilotica, ABTS radical scavenging

\footnotetext{
*Correspondence: a_muddathir@yahoo.com; muddathir@uofk.edu

'School of Molecular Life Science, Faculty of Applied Biological Science, Gifu University, 1-1 Yanagido, Gifu 501-1193, Japan

${ }^{2}$ Department of Horticulture, Faculty of Agriculture, University of Khartoum, Khartoum North-Shambat, Sudan

Full list of author information is available at the end of the article
}

(C) The Author(s). 2020 Open Access This article is licensed under a Creative Commons Attribution 4.0 International License, which permits use, sharing, adaptation, distribution and reproduction in any medium or format, as long as you give appropriate credit to the original author(s) and the source, provide a link to the Creative Commons licence, and indicate if changes were made. The images or other third party material in this article are included in the article's Creative Commons licence, unless indicated otherwise in a credit line to the material. If material is not included in the article's Creative Commons licence and your intended use is not permitted by statutory regulation or exceeds the permitted use, you will need to obtain permission directly from the copyright holder. To view a copy of this licence, visit http://creativecommons.org/licenses/by/4.0/ The Creative Commons Public Domain Dedication waiver (http://creativecommons.org/publicdomain/zero/1.0/) applies to the data made available in this article, unless otherwise stated in a credit line to the data. 


\section{Background}

Dental caries is an irreversible localized infection that results in progressive tooth decay [1]. It's a common type of dental disease associated with microorganisms present on the tooth surface in dental plaque. One of the main etiologic factors of dental caries is considered to be Streptococcus sobrinus, which belong to the grampositive mutans streptococci group. The presence of $S$. sobrinus is relatively higher on the molars compared to the anterior teeth $[1,2]$. Several epidemiological studies have shown that the prevalence of $S$. sobrinus is more closely associated with high caries activities [3]. S. sobrinus can colonize the tooth surface and initiate plaque formation by synthesizing water-insoluble glucan from sucrose by glucosyltransferases (GTF), resulting in a firm attachment to the tooth surface and form lactic and other organic acids by fermentation of various sugars in foods [4]. Different strategies for preventing dental caries caused by cariogenic bacteria, such as depression of the growth of streptococcus, inhibition of GTF activity, and hydrolysis of glucans by enzymes, have been developed [5]. Further accumulation of plaque around the gingival margin and subgingival region may lead to shifts in the balance of the microflora from mainly gram-positive bacteria to gram-negative bacteria, and an increased number of gram-negative anaerobic bacteria will cause the development of periodontal diseases [6].

Periodontal diseases are chronic inflammatory disorders of bacterial origin that affect tooth-supporting tissues [7]. Over 700 bacterial species that have been identified in the oral cavity [8], only a few are associated with periodontitis, including Porphyromonas gingivalis [9]. P. gingivalis is a gram-negative bacterium closely associated with chronic periodontitis. High numbers of $P$. gingivalis, together with other periodontopathogens, induce a host immune response, which in turn leads to a destructive inflammatory process.

Oxidative stress observed in a diseased periodontium could result directly from excess reactive oxygen species (ROS) activity or antioxidant deficiency or indirectly by creating a pro-inflammatory state. Some studies reported that the excess production of ROS resulted in damages of gingival tissues, periodontal ligament, and alveolar bone [10-12]. Therefore, the search for an antioxidant that could be used to control these diseases as polyphenolic compounds are likely candidates [13].

Acacia nilotica (L.) Delile sub nilotica (Leguminosae) is a tree found in the central and northern parts of Sudan and is known in Sudanese folk medicine by the common name 'Garad or Sunt.' The fruit and the stem bark are regarded as a tonic and astringent and are used internally to treat colds, bronchitis, pneumonia, diarrhea, and dysentery $[14,15]$. Fractionation of $A$. nilotica leaves and bark showed the presence of phenols condensed tannin [16], gallic acid, $(+)$ catechin, $(-)$ epigallocatechin-7-g'allate, catechin derivatives $[17,18]$, ellagic acid, kaempferol, and quercetin [19]. Parallelly many researches demonstrated its wide array of pharmacological activities, such as antiHIV-1 protease [20], antibacterial [21], antioxidant, anticarcinogenic [22, 23] and anti-inflammatory activities [24]. In Sudanese and Indian traditional medicine, gargle the decoction of the A. nilotica bark is used to strengthens teeth and eliminates toothache [25-27]. Even though there is a little investigation on the potential beneficial effects of $A$. nilotica bark on oral health. Thus, we evaluated the effects of $A$. nilotica bark methanolic extract and its fractions on the growth of two oral bacteria included $S$. sobrinus and $P$. gingivalis. We also investigated their GTF inhibitory activity and antioxidant functions for oral hygiene purposes.

\section{Methods}

\section{Reagents}

All materials purchased from (Wako-Japan) except piodonitrotetrazolium violet from (Sigma-Aldrich-Japan).

\section{Plant materials and extraction}

A. nilotica bark was collected from Sennar State, Sudan in May 2013 and then authenticated by the University of Khartoum, Faculty of Forest. Voucher specimens (SDSS-01) are deposited in the Horticultural Laboratory, Department of Horticulture, Faculty of Agriculture, University of Khartoum. A. nilotica bark was shade dried and powdered before being extracted with methanol for $12 \mathrm{~h}$ three times. The extracts were filtered through Whatman No. 2 filter paper, and the solvent was removed under vacuum using a rotary evaporator.

\section{Fractionation of $A$. nilotica bark}

The crude extract ( $400 \mathrm{mg} / 2 \mathrm{ml}$ of $50 \%$ methanol) was applied to a Sephadex LH-20 column. The column was eluted with methanol $(250 \mathrm{ml})$, methanol-water (80:20, v/v; $150 \mathrm{ml}$, Fr1), methanol-water $(50: 50, \mathrm{v} / \mathrm{v} ; 250 \mathrm{ml}$, Fr2), methanol-water (5:95, v/v; $100 \mathrm{ml}, \mathrm{Fr} 3)$ and finally acetone-water $(70: 30, \mathrm{v} / \mathrm{v} ; 250 \mathrm{ml}, \mathrm{Fr} 4)$. The fractions (Fr1-4) were concentrated in vacuo $\left(38^{\circ} \mathrm{C}\right)$ and freezedried to give four powders with approximate weights of $34.2 \mathrm{mg}, 35.7 \mathrm{mg}, 44.8 \mathrm{mg}$, and $244.5 \mathrm{mg}$ for Fr1, Fr2, Fr3, and Fr4 respectively. Furthermore, the crude extract and fractions were subjected to high performance liquid chromatography (HPLC) with reversed-phase column $\mathrm{C}_{18}$ (Sunniest $4.5 \mathrm{~mm}$ i.d. X $250 \mathrm{~mm}$ ). The solvent system used was as follows: a gradient program for $65 \mathrm{~min}$ from 5 to $100 \%$ methanol in water with $0.05 \%$ TFA (Trifluoroacetic acid) at a flow rate of $1 \mathrm{ml} / \mathrm{min}$, monitored at $280 \mathrm{~nm}$. 


\section{Antibacterial activity assay}

Minimum inhibitory concentration (MIC) was determined by the broth dilution method [28]. S. sobrinus 6715 and P. gingivalis ATCC 33277 were cultured in brain heart infusion broth. For $P$. gingivalis broth supplemented with $0.5 \mu \mathrm{g} / \mathrm{ml}$ vitamin $\mathrm{K}_{3}$ and $5 \mu \mathrm{g} / \mathrm{ml}$ hemin. The samples were tested for antibacterial activity in sterile 96-well plates. The inoculums were prepared by diluting the broth culture to $10^{6} \mathrm{cell} / \mathrm{ml}$ for $S$. sobrinus and $10^{8} \mathrm{cell} / \mathrm{ml}$ for $P$. gingivalis approximately. The experiments were performed in triplicate. Chlorhexidine was included in the assay as a positive control. Then cultures were incubated $24 \mathrm{~h}$ for $S$. sobrinus and $72 \mathrm{~h}$ for $P$. gingivalis at $37{ }^{\circ} \mathrm{C}$ under anaerobic condition. Microbial growth was indicated by adding $50 \mu \mathrm{l}$ of $(0.2 \mathrm{mg} / \mathrm{ml})$ p-iodonitrotetrazolium violet (INT) to culture and incubated at $37^{\circ} \mathrm{C}$ for $2 \mathrm{~h}$. The MIC was defined as the lowest concentration that inhibited the color change of INT [29]. For minimum bactericidal concentration (MBC), $10 \mu \mathrm{l}$ from wells that showed no color change were transferred to $100 \mu \mathrm{l}$ of fresh media and then incubated for $24 \mathrm{~h}$ under the anaerobic condition at $37^{\circ} \mathrm{C}$. Microbial growth was also indicated by adding INT to culture. The MBC was defined as the lowest concentration that inhibited the color change of INT.

\section{Preparation of glucosyltransferase (GTF)}

S. sobrinus 6715 was grown for $20 \mathrm{~h}$ at $37^{\circ} \mathrm{C}$ in $4 \mathrm{~L}$ of Todd Hewitt broth. After centrifugation of the culture at $1300 \mathrm{~g}$ for $10 \mathrm{~min}$ at $4{ }^{\circ} \mathrm{C}$, the cells were collected and then extracted with $8 \mathrm{M}$ urea for $1 \mathrm{~h}$ with stirring. The crude enzyme solution containing urea was dialyzed against $10 \mathrm{mM}$ sodium phosphate buffer ( $\mathrm{pH}$ 6) until the urea was removed entirely. One milliliter of the crude enzyme solution was pipetted into a microtube and stored in a freezer at $-80^{\circ} \mathrm{C}[30]$.

\section{GTF inhibitory activity assay}

Insoluble glucan synthesized by GTF was measured turbidimetrically. GTF was incubated in $300 \mu \mathrm{l}$ of $0.1 \mathrm{M}$ phosphate buffer ( $\mathrm{pH} 6.0$ ) containing $1 \%$ sucrose, $0.5 \%$ dextran $\mathrm{T}-10$, and in the presence or absence of samples at $37^{\circ} \mathrm{C}$ for $3 \mathrm{~h}$. The volume of the crude GTF solution used in the assay was determined by absorbance of around 1.0 at $590 \mathrm{~nm}$. Chlorhexidine was used as a positive control [30]. The inhibition rate is expressed by the following equation: Inhibition (\%) $=100 \times($ Ac - As $) /$ Ac.

Where.

Ac: Absorbance of the control.

As: Absorbance of the sample.

\section{ABTS radical scavenging activity assay}

2,2' -azino-bis (3-ethylbenzothiazoline-6-sulfonic acid diammonium salt) was dissolved in water to make a concentration of $7 \mathrm{mM}$. $\mathrm{ABTS}^{+}$was produced by reacting to the ABTS stock solution with $2.45 \mathrm{mM}$ potassium persulfate and allowing the mixture to stand in the dark at room temperature for $12-16 \mathrm{~h}$ before use. For the study of samples, the $\mathrm{ABTS}^{+}$was diluted with phosphate-buffered saline $5 \mathrm{mM}, \mathrm{pH} 7.4$ to obtain an absorbance of 0.70 at $734 \mathrm{~nm}$. After the addition of $980 \mu \mathrm{l}$ of diluted ABTS to $20 \mu \mathrm{l}$ of samples, the absorbance reading was taken five minutes after the initial mixing [31]. Trolox was used as a positive control. The activity was measured as follows:

$\%$ ABTS scavenging activity $=$.

[(control absorbance - sample absorbance)/ (control absorbance) $] \times 100$.

\section{Statistical analysis}

The inhibitory activity of GTFs and antioxidant activities were expressed as the mean (mean \pm standard deviation) value. The significant differences between samples were assessed by one-way analysis of variance (ANOVA) followed by pairwise comparison of the mean using Tukey's multiple comparison test. Values were determined to be significant when $p$ was less than $0.05(p<0.05)$.

\section{Results}

\section{Chromatogram data}

Typical chromatograms of crude methanolic extract and fractions are shown in Fig. 1. The chromatographic peaks of Fr1 and Fr2 were identified according to a commercial standard of gallic acid (GA) and methyl gallate (MG) (Figs. 2, 3). Therefore, the Fr1 contained a GA at the retention time $9.9 \mathrm{~min}$ as the main compound. Fr2 contained a mixture of GA and MG at the retention time 9.9 and $16.8 \mathrm{~min}$, respectively, in addition to unknown compound at the retention time of $41.6 \mathrm{~min}$. In contrast, compounds in the other fractions are still unidentified.

\section{Antibacterial activity}

In this study, the antibacterial MIC and MBC values of the $A$. nilotica bark and it's fractions against $S$. sobrinus and $P$. gingivalis using dilution methods were presented in Table 1. The MIC values of $0.5 \mathrm{mg} / \mathrm{ml}$ or less were considered as good antibacterial activity. Generally, Fr2, Fr1 and crude extract demonstrated good MIC values against S. sobrinus and P. gingivalis. MIC value of 0.3 $\mathrm{mg} / \mathrm{ml}$ was observed when Fr1 and Fr2 were used against $P$. gingivalis. Fr2 showed the best antibacterial activity against the two types of bacteria. Positive control demonstrated the most potent inhibition activity against the two types of bacteria.

\section{GTF inhibitory activity}

Fraction four (Fr4), methanolic crude extracts of A. nilotica bark, and Fr3 at the concentration of $100 \mu \mathrm{g} / \mathrm{ml}$ inhibited GTF secreted from $S$. sobrinus to a remarkable extent with more than $85 \%$ inhibitions (Table 2). Judging 


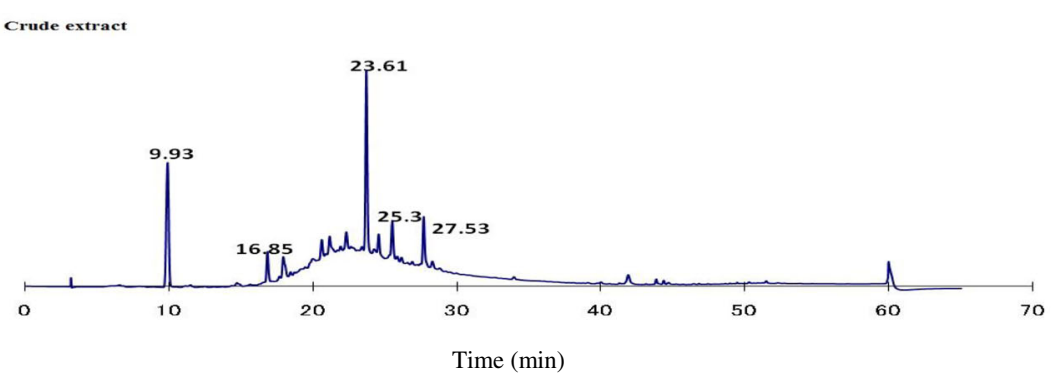

Fr1

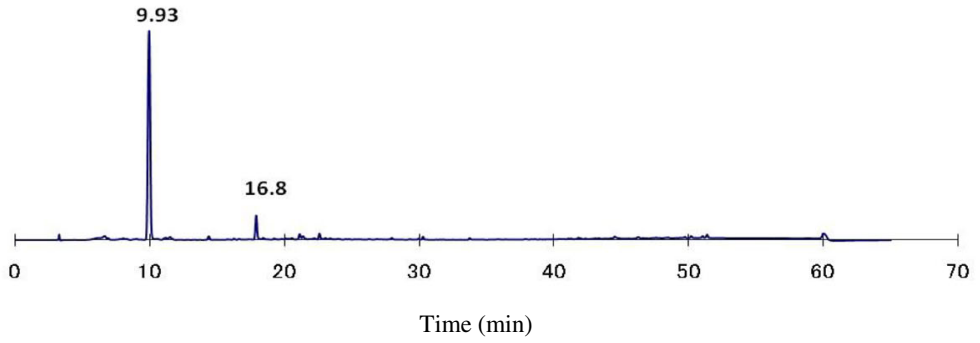

Fr2

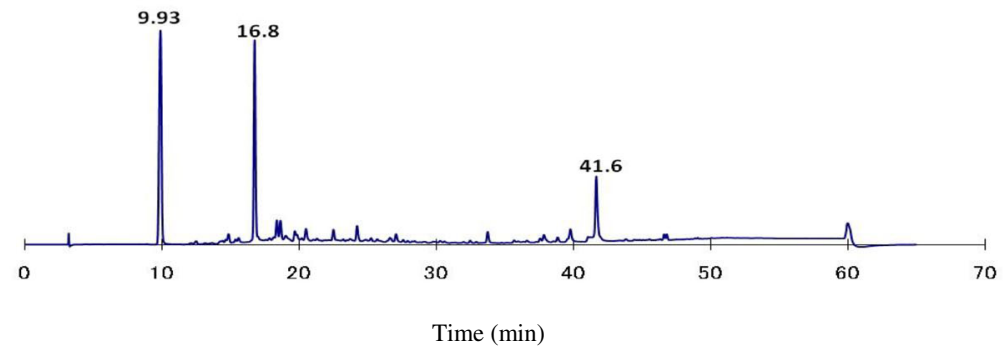

Fr3

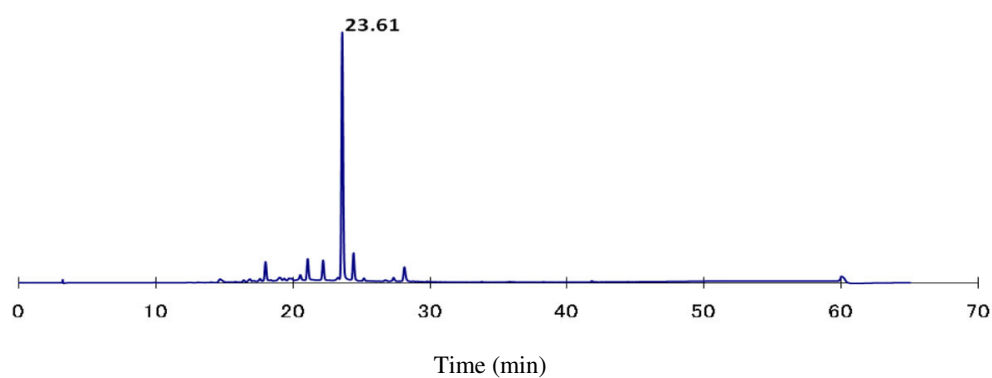

Fr4

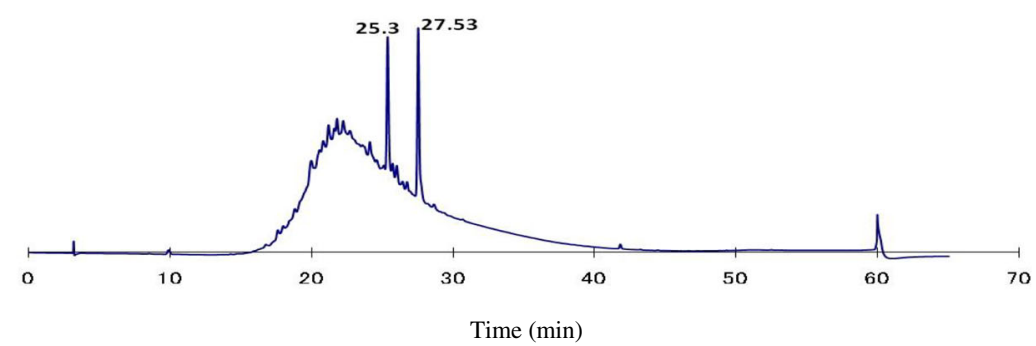

Fig. 1 HPLC chromatogram of Acacia nilotica crude extract and its fractions (F1-F4) 


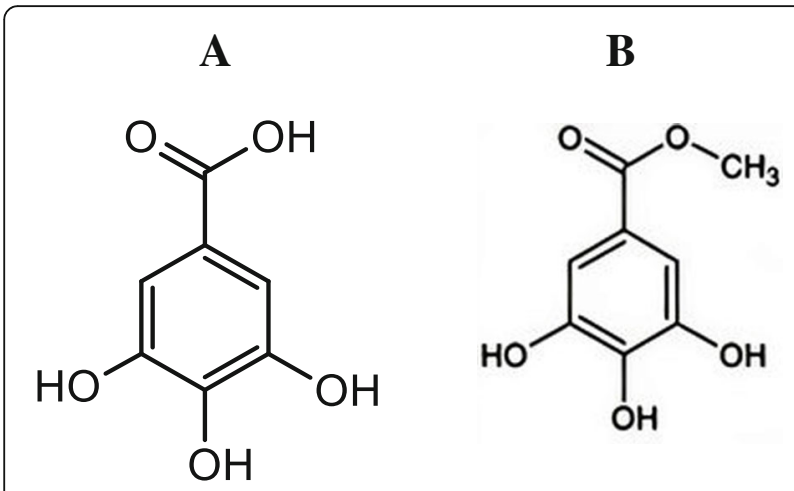

Fig. 2 Molecular structure of gallic acid and methyll gallate. A: Gallic acid. B: Methyll gallate

from the $\mathrm{IC}_{50}$ values; $\mathrm{Fr} 4$, and methanolic crude extracts showed remarkable inhibition of GTF activity with $\mathrm{IC}_{50}$ values of 3.9 and $8.4 \mu \mathrm{g} / \mathrm{ml}$, respectively (Table 2). Chlorhexidine, as a positive control, showed good activity against GTF.

\section{ABTS radical scavenging activity}

$\mathrm{IC}_{50}$ value is the effective concentration at which antioxidant activity is $50 \%$. The ABTS radical scavenging activity $\left(\mathrm{IC}_{50}\right)$ of crude extracts and fractions were ranged between $0.8-5.2 \mu \mathrm{g} / \mathrm{ml}$ (Fig. 4). The results also revealed that Fr1 had a significant antioxidant activity with an $\mathrm{IC}_{50}$ value of $0.8 \mu \mathrm{g} / \mathrm{ml}$ compared to the trolox as a positive control $(2.1 \mu \mathrm{g} / \mathrm{ml})$. As described previously, the gallic acid was the main compound in this Fraction. Fraction three (Fr3) also demonstrated an excellent antioxidant activity in which there were no significant differences between $\operatorname{Fr} 3(3.1 \mu \mathrm{g} / \mathrm{ml})$ and positive control.

\section{Discussion}

\section{Chromatogram data}

HPLC analysis is the best way for the chemical profiling of plant extract. The described method showed relatively good separation of specific fractions. Identification of phenolic compounds in methanolic extract of $A$. nilotica bark was carried out by using the available standards (GA and MG) as shown in Fig. 3. In the present study, Fr1 and F2 contained a GA and mixture GA and MG respectively. These results were in agreement with Sharma et al. [32] and Leela et al. [33]. They isolated and purified GA and MGfrom A. nilotica bark through open column chromatography and HPTLC. In contrast, Sadiqa et al. [34] reported that quantification of bark extract of $A$. nilotica collected from Pakistan by using HPLC/DAD showed that catechin, isoquercetin, tannic acid and quercetin contained in considerable quantities. However, the gallic acid was found in leaves and pods only. Also, Zhang and Lin [35] stated that the broad peaks in HPLC chromatogram spectra indicated that there was a large structural heterogeneity with different degrees of polymerization. Fr4 HPLC chromatogram contains a broad peak after 17 min retention time (Fig. 1). This broad peak was suggested to be a mixture of higher molecular weight of proanthocyanidins (condensed tannins).

\section{Antibacterial properties}

Several authors suggested that the effective antimicrobial agents from herbal extracts along with their derived materials against cariogenic and periodontopathic bacteria, could form an important part preventing dental caries and periodontal diseases [36, 37]. Gibbons [38] suggested that isolated phytochemicals should have $\mathrm{MIC}<1$ $\mathrm{mg} / \mathrm{ml}$, therefore in this study MIC value of $0.5 \mathrm{mg} / \mathrm{ml}$ or less for S. sobrinus and P. gingivalis was considered as a good antibacterial. Even though gram-negative bacteria are more resistant than gram-positive due to the presence of outer membrane, which acts as a barrier to environmental substances, including antibiotics [39, 40]. The observed activity of Fr1 and Fr2 against gramnegative bacteria ( $P$. gingivalis) could be explained by the fact that the active compounds might act by inhibiting the bacterial growth without necessarily penetrating into the bacterial cell itself [41]. In earlier studies, extracts of the A. nilotica pods displayed antibacterial activity against Staphylococcus aureus with MIC value of $0.4 \mathrm{mg} / \mathrm{ml}$. Abdel Nabi et al. [21] suggested that the antimicrobial activity of $A$. nilotica fruit extract $(\mathrm{MIC}=$ $0.05-1.6 \mathrm{mg} / \mathrm{ml}$ ) was not due to tannins but to another substance(s). A. nilotica bark and leaves showed good antibacterial activities against some gram-positive and gram-negative bacteria [42-44]. Furthermore, $A$. nilotica bark has been shown to contain simple phenolic compounds like GA and MG, which have often been implicated in antibacterial activity. Deshpande and Kadam [45] reported that ethanol extract of $A$. nilotica bark showed activity against $S$. mutans with MIC value of 5 $\mathrm{mg} / \mathrm{ml}$. The results obtained in this study are similar to Kang et al. [46], who reported that both GA and MG had inhibitory effects on the growth of cariogenic $(\mathrm{MIC}=8 \mathrm{mg} / \mathrm{ml})$ and periodontopathic bacteria $(\mathrm{MIC}=$ $1 \mathrm{mg} / \mathrm{ml}$ ). Hence, MG and GA might be used to prevent the formation of oral biofilms. However, MG was more effective in inhibiting bacterial growth and formation of S. mutans biofilm than GA.

\section{Enzyme inhibitory activity}

Mutans streptococci group colonize at the tooth enamel surface and initiate plaque formation by their ability to make extracelluar polysaccharides from sucrose using glucosyltransferase which is a major component in the development of dental caries [47]. The previous report mentioned that methanolic extracts of $A$. nilotica bark contained a considerable amount of condensed tannins 


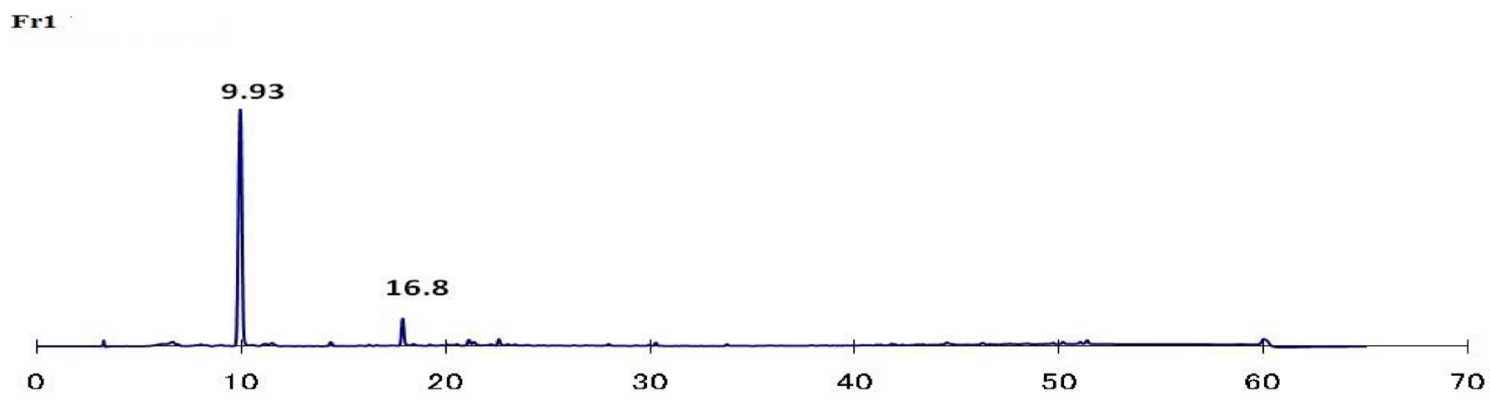

Time (min)

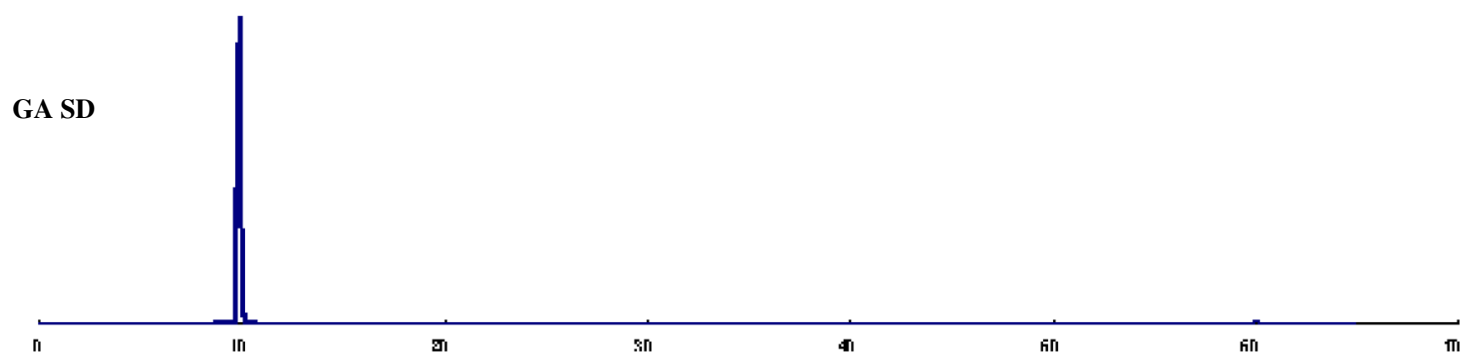

Time (min)

Fr2

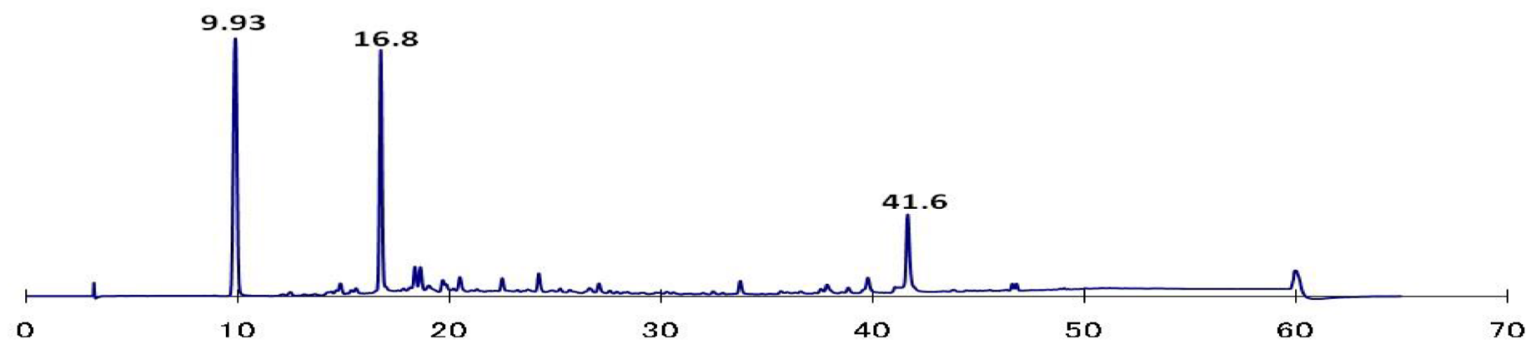

Time (min)

MG SD

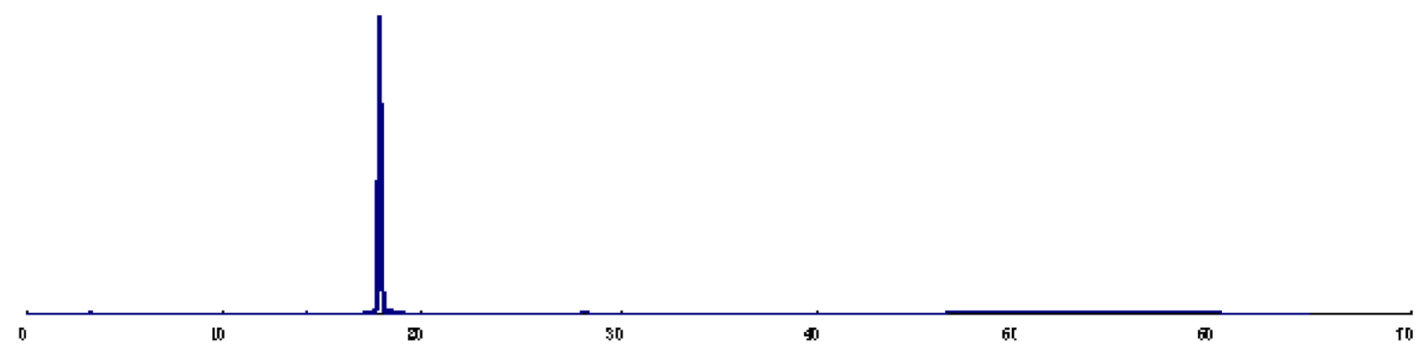

Time (min)

Fig. 3 HPLC chromatogram of isolated fractions from A. nilotica (F1 and F2) and commercial standard (GASD: Gallic acid standard; MGSD: Methyl gallate standard) 
Table 1 Antibacterial activities of Acacia nilotica bark and their fractions against Streptococcus sobrinus and Porphyromonas gingivalis

\begin{tabular}{|c|c|c|c|c|}
\hline \multirow[t]{2}{*}{ Samples } & \multicolumn{2}{|c|}{ Streptococcus sobrinus } & \multicolumn{2}{|c|}{ Porphyromonas gingivalis } \\
\hline & MIC mg/ml & MBC $\mathrm{mg} / \mathrm{ml}$ & $\mathrm{MIC} \mathrm{mg} / \mathrm{ml}$ & $\mathrm{MBC} \mathrm{mg} / \mathrm{ml}$ \\
\hline Crude extract & 0.5 & 2 & 0.5 & 2 \\
\hline Fr1 & 0.5 & $-^{a}$ & 0.3 & 4 \\
\hline $\mathrm{Fr} 2$ & 0.5 & 1 & 0.3 & 1 \\
\hline Fr3 & 1 & - & 0.5 & - \\
\hline Fr4 & 0.5 & - & 1 & - \\
\hline Chlorhexidine $^{b}$ & 0.0004 & 0.0004 & 0.0004 & 0.0004 \\
\hline
\end{tabular}

${ }^{\mathrm{a} M B C}$ was not detected

bositive control

[48]. The HPLC chromatogram of F4 indicated the presence of condensed tannins. This type of tannin is available in barks, oolong tea, green tea and grape seed, which are potent GTF inhibitors owing to their polyphenolic moiety being able to form hydrogen bonds with GTF [5]. Besides, high molecular weight plant polyphenols displaying strong anti-GTF activity have a common structural feature shared with catechin-based oligomeric forms (condensed tannins) [49]. Chlorhexidine showed potent inhibitory activities against two types of bacteria and GTF enzyme. However, it has been reported that chlorhexidine is cytotoxic to human periodontal ligament cells, inhibits protein synthesis, and affects mitochondrial activity, thus having detrimental effects on vital tissues [50, 51].

\section{Antioxidant activity}

The role of antioxidants is to remove harmful oxidants or (ROS) as soon as they form or to repair the damage caused by ROS. Numerous antioxidants have been tried and tested both by systemic administration and as mouthwashes. These include synthetic products like vitamins to natural products like wine and green tea [52, 53]. Additionally, few studies were carried out on the antioxidant activity of oral hygiene products. Battino et al. [54] showed that a few antioxidant-enriched toothpastes displayed a clear antioxidant activity. In vivo assay, Tamaki et al. [55] stated that the oral administration of resveratrol improves

Table 2 The inhibitory activities of Acacia nilotica bark and their fractions against glucosyEltransferase (GTFs) enzyme

\begin{tabular}{lll}
\hline Samples & Inhibitory activity (\%) at $\mathbf{1 0 0} \mathbf{\mu g} / \mathbf{m l}$ & $\mathbf{I C}_{\mathbf{5 0}} \mathbf{\mu g} \mathbf{m} \mathbf{~}$ \\
\hline Crude extract & $90.1 \pm 1.53^{\mathrm{a}, \mathrm{b}}$ & $08.4 \pm 3.8^{\mathrm{a}}$ \\
Fr1 & $02.57 \pm 3.57^{\mathrm{d}}$ & $>100$ \\
Fr2 & $59.7 \pm 4.76^{\mathrm{c}}$ & $89.4 \pm 4.1^{\mathrm{c}}$ \\
Fr3 & $85.7 \pm 0.85^{\mathrm{b}}$ & $35.4 \pm 19.4^{\mathrm{b}}$ \\
Fr4 & $92.8 \pm 0.71^{\mathrm{a}}$ & $03.9 \pm 2.7^{\mathrm{a}}$ \\
Chlorhexidine $^{*}$ & $90.2 \pm 0.12^{\mathrm{a}, \mathrm{b}}$ & $05.7 \pm 4.2^{\mathrm{a}}$ \\
\hline
\end{tabular}

Means with different letters in the same column were significantly different at the level $(p<0.05) ; n=3$

* Positive control oxidative stress and prevents the progression of periodontitis in a rat periodontitis model. In this study, the antioxidant assay is based on the ability of an antioxidant to scavenge ABTS radicals. It is a simple, rapid and inexpensive antioxidant assay usually used for the evaluation of antioxidant capacity [56]. The ABTS radical is soluble in water and organic solvents, enabling the determination of the antioxidant capacity of both hydrophilic and lipophilic samples [57]. The finding in this study agreed with Sohi et al. [58]. They stated that pretreatment of peripheral blood lymphocytes with gallic acid effectively inhibit lipid peroxidation and apoptosis induced by oxidative stress and it was found to be a stronger antiradical than trolox.

Furthermore, our results support the reports of Sultana et al.; Singh and Arora [59,60] who reported that A. niloica bark extracts showed a strong antioxidant activity by using DPPH radical scavenging activity assay. Houde et al. [13] demonstrated that proanthocyanidins contained in grape seed extracts were potent antioxidant properties and should be considered a potential agent in the prevention of periodontal diseases. So, it is not surprising that our extract, which is rich in polyphenolic compounds, possessed high antioxidant activity and it could be used for oral hygiene.

Therefore in the present study, we showed that the crude extract of $A$. nilotica and their fractions can affect bacterial and GTF enzyme viability. Furthermore, some fractions showed significant antioxidant activity. The might be proposed mechanisms of action to explain the crude extract or their fractions antimicrobial activities, including direct action on microbial metabolism through inhibition of oxidative phosphorylation or inhibition of extracellular microbial enzymes required for microbial growth. Another overlooked advantage of GTF-targeting inhibitors is their potential to possess anti-biofilm activity without being (with less) bactericidal, thus providing alternative methods to prevent biofilm-related diseases with minimal effect on the ecological balance in the microbial community [61]. Also, Jeon et al. [62] reported that caries antagonistic activity of antioxidants polyphenols had been attributed to three main mechanisms (i) 


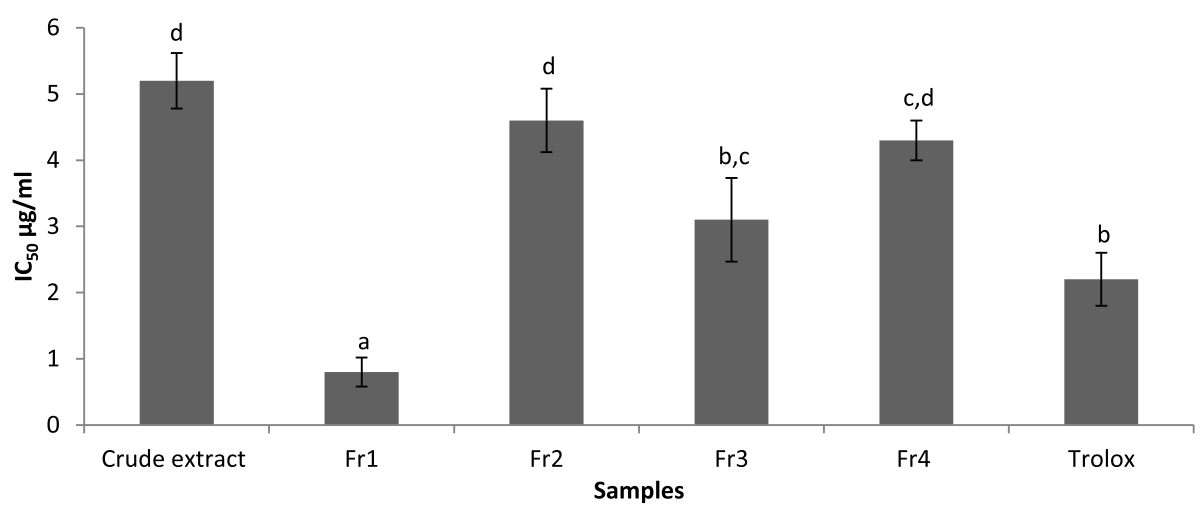

Fig. 4 Free radical scavenging properties of A. nilotica bark and its fractions by using ABTS photometric assay. Values not followed by a common letter were significantly different at the level $(p<0.05)$

Direct antimicrobial effect by killing the responsible bacteria, (ii) Inhibition of extracellular polysaccharide production, and (iii) Impairment of bacterial adhesion.

\section{Conclusions}

The results of the present study suggest that besides antibacterial potentiality and GTF inhibitory activity of A. nilotica bark may be used as adjuvant antioxidants in mouthwashes and may provide treatment strategies for periodontal diseases in the future. However, additional tests including identify the rest of the active compounds, cytotoxicity assay, experimental models and the pharmacological applicability are required soon.

\section{Abbreviations}

GTF: Glucosyltransferases; ROS: reactive oxygen species; Fr: Fractions; HPLC: High performance liquid chromatography; TFA: Trifluoroacetic acid; MIC: Minimum inhibitory concentration; INT: P-iodonitrotetrazolium violet: MBC: Minimum bactericidal concentration; ABTS: 2,2'-azino-bis (3ethylbenzothiazoline-6-sulfonic acid diammonium salt); ANOVA: Analysis of variance; GA: Gallic acid; MG: Methyl gallate; DPPH: 1, 1-diphenyl-2picrylhydrazyl

\section{Acknowledgements}

The authors would like to thank Dr. Enas Y. Abdel Kareem from the University of Khartoum, Faculty of Forest, for her assistance in plant identification and authentications. A. M and EBMM acknowledge for Gifu University, Japan.

\section{Authors' contributions}

A.M participated in the design of the study, collection and extraction of plant sample, fractionation process, and wrote the manuscript. E.A.M.M participated in antibacterial, enzyme assay and helped to draft the manuscript. T. M supervised and designs this study. All the authors read and approved the final version of the manuscript.

\section{Funding}

No fund was available.

\section{Availability of data and materials}

The data sets that support the conclusions of this article are included in the article.

Ethics approval and consent to participate Not applicable.
Consent for publication

Not applicable.

\section{Competing interests}

The authors declare that they have no competing interests.

\section{Author details}

${ }^{1}$ School of Molecular Life Science, Faculty of Applied Biological Science, Gifu University, 1-1 Yanagido, Gifu 501-1193, Japan. Department of Horticulture, Faculty of Agriculture, University of Khartoum, Khartoum North-Shambat, Sudan. ${ }^{3}$ Faculty of Pharmacy, University of Science and Technology, Omdurman, Sudan.

Received: 8 May 2020 Accepted: 5 November 2020

Published online: 23 November 2020

References

1. Lindquest B, Emilson CG. Dental location of Streptococcus mutans and Streptococcus sobrinus in humans harborin both species. Caries Res. 1991;25:146-52

2. Schupbach P, Osterwalder V, Guggenheim B. Human roots caries: microbiota in plaque covering sound, carious and arrested carious root surfaces. Caries Res. 1995;29:382-95.

3. Fujiwara T, Sasada EE, Mima N, Ooshima T. Caries prevalence and salivary mutans streptococci in 0-2 year old children of Japan. Comm Dent Oral Epidemiol. 1991;19:151-4.

4. Sawamura S, Tonosaki Y, Hamada S. Inhibitory effect of ellagic acid on glucosyltransferase from mutans streptococci. Biosci Biotechnol Biochem. 1992:56:766-8.

5. Kuspradini $\mathrm{H}$, Ohashi H, Mitsunaga T. Antimicrobial activity against Streptococcus sobrinus and glucosyltransferase inhibitory activity of taxifolin and some flavanonol rhamnosides from kempas (Koompassia malaccensis) extracts. J Wood Sci. 2009:55:308-13.

6. Marsh PD. Microbial ecology of dental plaque and its significance in health and disease. Adv Dent Res. 1994;8:263-71

7. Highfield J. Diagnosis and classification of periodontal disease. Aust Dent J. 2009;54:11-26.

8. Aas JA, Paster BJ, Stokes LN, Olsen I, Dewhirst FE. Defining the normal bacterial flora of the oral cavity. J Clin Microbiol. 2005;43:5721-32.

9. Holt SC, Ebersole JL. Porphyromonas gingivalis, Treponema denticola, and Tannerella forsythia: the "red complex", a prototype polybacterial pathogenic consortium in periodontitis. Periodontol. 2000;2005(38):72-122.

10. Batista AC, Silva TA, Chun JH, Lara VS. Nitric oxide synthesis and severity of human periodontal disease. Oral Dis. 2002;8:254-60.

11. Tsai CC, Chen HS, Chen SL, Ho YP, Ho KY, Wu YM, Hung CC. Lipid peroxidation: a possible role in the induction and progression of chronic periodontitis. J Periodontal Res. 2005:40:378-84.

12. Canakci CF, Cicek Y, Canakci V. Reactive oxygen species and human inflammatory periodontal diseases. Biochemistry (Mosc). 2005;70:619-28.

13. Houde V, Grenier D, Chandad F. Protective effects of grape seed proanthocyanidins against oxidative stress induced by lipopolysaccharides of periodontopathogens. J Periodontol. 2006;77:1371-9. 
14. Pousset $J$. Plantes medicinales africaines utilisation practique. Paris: Agence de cooperation culturelle et technique; 1989. p. 13-5.

15. Watt JM, Breyer-Brandwijk MG. The medicinal and poisonous plants of southern and eastern Africa. Edinburgh: Livingstone Ltd; 1962. p. 546.

16. Mnisi CM, Mlambo V. Influence of harvesting site on chemical composition and potential protein value of Acacia erioloba, A. nilotica and Ziziphus mucronata leaves for ruminants. J Anim Physiol Anim Nutr. 2016;5:1-10. https://doi.org/10.1111/jpn.12535.

17. Kaur K, Michael H, Arora S, Härkönen P, Kumar S. In vitro bioactivity-guided fractionation and characterization of polyphenolic inhibitory fractions from Acacia nilotica (L.) Willd. Ex Del. J Ethnopharmacol. 2005;99:353-60.

18. Singh R, Singh B, Singh S, Kumar N, Kumar S, Arora S. Anti-free radical activities of kaempferol isolated from Acacia nilotica (L.) Willd, ex. Del. Toxicolo In Vitro. 2008;22:1965-70.

19. Al-Nour MY, Ibrahim MM, Elsaman T. Ellagic acid, kaempferol, and quercetin from Acacia nilotica: promising combined drug with multiple mechanisms of action. Curr Pharmacol Rep. 2019;5:255-80. https:/doi.org/10.1007/s40495-019-00181-w.

20. Hussein G, Miyashiro H, Nakamura N, Hattori M, Kawahata T, Otake T, Kakiuchi $\mathrm{N}$, Shimotohno K. Inhibitory effects of Sudanese medicinal plant extracts on HIV-1 replication and HIV-1 protease. Phytother Res. 1999;13:31-6.

21. Abdel Nabi OM, Reisinger EC, Reinthaler FF, Still F, Eibel U, Krejs GJ. Antimicrobial activity of Acacia nilotica (L.) Willd. Ex Del. Var. nilotica (Mimosaceae). J Ethnopharmacol. 1992;37:77-9.

22. Maldini M, Montoro P, Al H, Mahalel UA, Oleszek W, Stochmal A, Piacente S. Strong antioxidant phenolics from A nilotica: profiling by ESI-MS and qualitativequantitative determination by LC-ESI-MS. J Pharm Biomed Anal. 2011;56:228-39.

23. Pattnaik S, Mani S, Rajkumari J. SJ Sudharshan, Madhu D, Busi S. determination of antioxidant potential of Acacia nilotica leaf extract in oxidative stress response system of Saccharomyces cerevisiae. J Sci Food Agric. 2017;15:5247-53. https://doi.org/10.1002/jsfa.8409.

24. Dafallah AA, Al-Mustafa Z. Investigation of the anti-inflammatory activity of Acacia nilotica and Hibiscus sabdariffa. Am J Chin Medi. 1996;24:263-9.

25. Kabbashi AS, Garbi MI, Osaman EE. Antigiardial, antioxidant activities and cytotoxicity of ethanolic extract of leaves of Acacia nilotica (L). Adv Med Plant Res. 2015;3:33-8.

26. Van Wky B, Van Wky P, Van Wky BE. Photographic guide to tree of southern Africa. Pertoria: Briza publications; 2000.

27. Ali A, Akhtar N, Khan BA, Khan MS, Rasul A, Zaman SU, Khaild N, Wasseem K, Mahmood T, Ali L. Acacia nilotica: a plant of multipurpose medicinal uses. J Med Plant Res. 2012:61492-6.

28. Iwaki K, Koya-Miyata S, Kohno K, Ushio S, Fukuda S. Antimicrobial activity of Polygonum tinctorium Lour: extract against oral pathogenic bacteria. J Nat Med. 2006:60:121-5.

29. Eloff JN. Antibacterial activity of Marula (Sclerocarya birrea(a.rich) Hochst. Subsp. caffra (Sond) Kokwaro)(Anacardiaceae) bark and leaves. J Ethnopharmacol. 2011;76:305-8.

30. Mitsunaga $\mathrm{T}$, Abe I, Kontani M, Ono H, Tanaka T. Inhibitory effects of bark proanthocyanidins on the activities of glucosyltransferases of Streptococcus sobrinus. J Wood Chem Technol. 1997:17:327-40.

31. Fellegrin $N$, Ke R, Yang M, Rice-Evans C. Screening of dietary carotenoids and carotenoid-rich fruit extracts for antioxidant activities applying 2, 2'azinobis (3-ethylbenzothiazoline-6-sulfonic acid) radical cation decolorization assay. Methods Enzymol. 1999:299:379-89.

32. Sharma M, Gupta AK, Mukherji A. Invasive Acacia nilotica a problematic weed is a source of potent methyl gallate. IJSR. 2014;10:1193-5.

33. Leela V, Kokila L, Lavanya R, Saraswathy A, Brindha P. Determination of gallic acid in Acacia nilotica Linn. By HPTLC. IJPT. 2010;2:285-92.

34. Sadiq MB, Hanpithakpong W, Tarning J, Anala AK. Screening of phytochemicals and in vitro evaluation of antibacterial and antioxidant activities of leaves, pods and bark extracts of Acacia nilotica (L.) Del. Ind Crop Prod. 2015;77:873-82

35. Zhang LL, Lin YM. Tannins from Canarium album with potent antioxidant activity. J Zhejiang Univ Sci B. 2008:5:407-15

36. Watanabe T, Katayama S, Matsubara M, Honda Y, Kuwahara M. Antibacterial carbohydrate monoesters suppressing cell growth of Streptococcus mutans in the presence of sucrose. Curr Microbiol. 2000;41:210-3.

37. Kim JE, Kim HE, Hwang JK, Lee HJ, Kwon HK, Kim Bl. Antibacterial characteristics of Curcuma xanthorrhiza extract on Streptococcus mutans biofilm. J Microbiol. 2008:46:228-32.

38. Gibbons S. Plants as a source of bacterial resistance modulators and antiinfective agents. Phytochem Rev. 2005;4:63-78.
39. Rabe T, Van Staden J. Antibacterial activity of south African plants used for medicinal purposes. J Ethnopharmacol. 1997:56:81-7.

40. Palombo EA, Semple SJ. Antibacterial activity of traditional Australian medicinal plants. J Ethnopharmacol. 2001;77:151-7.

41. Mulaudzi R, Ndhlala A, Kulkarni M, Finnie J, Van Staden J. Antimicrobial properties and phenolic contents of medicinal plants used by the Venda people for conditions related to venereal diseases. J Ethnopharmacol. 2011;135:330-7.

42. Sharma C, Aneja KR, Surain P, Dhiman R, Jiloha P, Meashi V, Kaur M. In vitro evaluation of anti-microbial spectrum of Acacia nilotica leaves and bark extracts against pathogens causing otitis infection. J Innov Biol. 2014;1:51-6.

43. Patel JD, Shrivastava AK, Kumar V. Evaluation of some medicinal plants used in traditional wound healing preparations for antibacterial property against some pathogenic bacteria. J Clin Immunol Immunopathol Res. 2009;1:7-12.

44. Deshpande SN. Preliminary phytochemical analysis and in vitro investigation of antibacterial activity of Acacia nilotica against clinical isolates. Pharmacogn Phytochem. 2013;5:23-7.

45. Deshpande SN, Kadam DG. Photochemical analysis and antibacterial activity of Acacia nilotica against Streptococcus mutans. Int J Pharm Pharm Sci. 2012;1:236-8.

46. Kang MS, Oh JS. Kang IC, Hong SJ, Choi CH. Inhibitory effect of methyl gallate and gallic acid on oral bacteria. J Microbiol. 2008;46:744-50.

47. Jacquelin LF, Brisset L, Magrex EL, Carquin J, Gelle MP, Choisy C. Prevention of cariogenic dental plaque. Study of the structures implicated in the adhesion and coaggregation in Streptococcus mutans and Streptococcus sobrinus. Pathol Biol (Paris). 1995:43:371-9.

48. Muddathir AM, Mitsunaga T. Evaluation of anti-acne activity of selected Sudanese medicinal plants. J Wood Sci. 2013;59:73-9.

49. Yanagida A, Kanda T, Tanabe M, Matsudaira F, Oliveira Cordeiro JG. Inhibitory effects of apple polyphenols and related compounds on cariogenic factors of mutans streptococci. J Agric Food Chem. 2000;48:5666-71.

50. Chang YC, Huang FM, Tai KW, Chou MY. The effect of sodium hypochlorite and chlorhexidine on cultured human periodontal ligament cells. Oral Surg Oral Med Oral Pathol Oral Radiol Endod. 2011;92:446-50.

51. Beaudouin E, Kanny G, Morisset M, Renaudin JM, Mertes M, Laxenarie MC, Mouton C, Jacson F, Moneret-Vautrin DA. Immediate hypersensitivity to chlorhexidine: literature review. Eur Ann Allergy Clin Immunol. 2004:36:123-6.

52. Atsumi T, Tonosaki K, Fujisawa S. Salivary free radical scavenging activity is affected by physical and mental activities. Oral Dis. 2008;14:490-6.

53. Diab-Ladki R, Pellat B, Chahine R. Decrease in the total antioxidant activity of saliva in patients with periodontal diseases. Clin Oral Investig. 2003;7:103-7.

54. Battino $\mathrm{M}$, Bullon $\mathrm{P}$, Wilson $\mathrm{M}$, Newman $\mathrm{H}$. Oxidative injury and inflammatory periodontal diseases: the challenge of anti-oxidants to free radicals and reactive oxygen species. Crit Rev Oral Biol Med. 1999;10:458-76.

55. Tamaki N, Cristina Orihuela-Campos R, Inagaki Y, Fukui M, Nagata T, Ito HO Resveratrol improves oxidative stress and prevents the progression of periodontitis via the activation of the Sirt1/AMPK and the Nrf2/antioxidant defense pathways in a rat periodontitis model. Free Radic Biol Med. 2014:75:222-9.

56. Gan RY, Kuang L, Xu XR, Zhang Y, Xia EQ, Song FL, Li HB. Screening of natural antioxidants from traditional Chinese medicinal plants associated with treatment of rheumatic disease. Molecules. 2010;15:5988-97.

57. Mohamed SA, Khan JA. Antioxidant capacity of chewing stick miswak Salvadora persica. BMC Complement Altern Med. 2013;40:1-6.

58. Sohi KK, Mittal N, Hundal MK, Khanduja KL. Gallic acid, an antioxidant, exhibits antiapoptotic potential in normal human lymphocytes: a $\mathrm{BCl}-2$ independent mechanism. J Nutr Sci Vitaminol (Tokyo). 2003;49:221-7.

59. Sultana B, Anwar F, Przybylski R. Antioxidant activity of phenolic components present in barks of Azadirachta indica, Terminalia arjuna, Acacia nilotica, and Eugenia jambolana lam. Trees. Food Chem. 2007:104:1106-14.

60. Singh $\mathrm{R}$, Arora $\mathrm{S}$. Attenuation of free radicals by acetone extract /fractions of Acacia nilotica (L.) Willd. Ex del. J Chin Clin Med. 2007:4:196-204.

61. Zhi R, Chen L, Li J, Li Y. Inhibition of Streptococcus mutans polysaccharide synthesis by molecules targeting glycosyltransferase activity. J Oral Microbiol. 2016:8:1-9. https://doi.org/10.3402/jom.v8.31095.

62. Jeon JG, Rosalen $\mathrm{PL}$, Falsetta $\mathrm{ML}, \mathrm{Koo} \mathrm{H}$. Natural products in caries research: current (limited) knowledge, challenges and future perspective. Caries Res. 2011;45:243-63. https://doi.org/10.1159/000327250.

\section{Publisher's Note}

Springer Nature remains neutral with regard to jurisdictional claims in published maps and institutional affiliations. 